\title{
PISTAS PARA A COMPREENSÃO DOS SIGNIFICADOS DO TRABALHO DAS MULHERES
}

\section{Maria Lúcia da Silveira}

Socióloga, Doutoranda do Programa de Pós Graduação em Ciências Sociais, PUC/SP

Este artigo propõe-se a refletir sobre a construção histórica e simbólica dos significados do trabalho das mulheres que configuraram possibilidades de identificação coletiva e, mais do que isso, a subjetividade presente nas formas de sociabilidade que o trabalho propicia, e os consequentes desafios identitários, ou novos agenciamentos coletivos que proporciona.

Palavras-chave: trabalho; divisão sexual do trabalho; gênero; identidade

É possível iniciar essa discussão optando por um modo de olhar o trabalho que o toma sobretudo como atividade social onde vão se entrelaçar diferentes subjetividades, e, portanto, como fundante de sociabilidades. (Freyssenet, 93).

As historiadoras G. Fraisse e M. Perrot, na introdução ao volume da História das Mulheres que focaliza o século XIX, observam que o trabalho das mulheres revela uma ambivalência que é preciso desvendar: "Porquê razão o trabalho das mulheres é tanto o lugar de uma sobre-exploração como de uma emancipação, e a sociedade política um espaço de exclusão e depois de reconhecimento?" (Fraisse e Perrot, 1991, p. 10)

Há que atualizar a pergunta do porquê, sobretudo quando nos dias que correm nos detemos no material cotidiano refletido seja nos jornais (enquetes, entrevistas, dados estatísticos, reportagens), seja nos estudos acadêmicos sobre o trabalho das mulheres. (Bruschini, 1994). Constatase que as mulheres saíram maciçamente para trabalhar fora de casa, seja por necessidade de contribuir no orçamento familiar, seja porque se tornaram elas próprias chefes de família em proporção crescente, seja por opção profissional e de vida. Enfrentam e arcam em sua maioria com uma dupla jornada de trabalho (em casa e fora dela, ou cada vez mais atualmente, trabalho à domicílio $\mathrm{e}$ serviço doméstico). Enfrentam condições estressantes no trabalho devido à existência de uma divisão sexual do trabalho, que envolve a desvalorização do trabalho feminino, com remuneração via de regra inferior à do homem em função similar, menores oportunidades ocupacionais e de carreira, condições de controle e vigilância redobradas, etc. Mas mesmo assim, a maior parte das mulheres não quer voltar-se apenas para a esfera doméstica ou privada.

As trajetórias das mulheres mostram que o conjunto de suas vidas se transformam e as respostas práticas que dão às relações de gênero no campo do trabalho, e a maneira de representá-lo são múltiplas e variadas: resistência, recusa, transgressão, subordinação, submissão, acomodação, rebeldia, são respostas possíveis.

As mulheres, no entanto, não são apenas vítimas. Existe uma dialética entre sujeição e liberdade que se vislumbra ao analisarmos os modos como as mulheres representam o trabalho. Várias experiências, diversos destinos de gênero, 
poderíamos dizer, beneficiando-nos de expressão utilizada pela socióloga Bete Lobo (Lobo, 1991).

\section{A construção histórica dos significados}

Imagens da mulher como trabalhadora vão se firmando ao longo do século XIX e configurando uma nova identidade para a mulher, que estará sempre em luta com a representação de gênero dominante e historicamente construída : a identificação primordial do mundo do trabalho como masculino e a vida no lar, doméstica, como vocação e destino natural das mulheres.

Ingressar no mundo público pela porta do trabalho, abre os horizontes para novas possibilidades e questinamentos da condição feminina e a constituição de novas subjetividades que se podem dizer, nomear, expressar, individual e coletivamente, para além do silêncio das quatro paredes do espaço doméstico.

Perrot mostra, no entanto, que as mulheres estiveram em cena, nas ruas, nos trabalhos sociais, na maior parte das vezes, invisíveis ao olhar dos historiadores tradicionais. Isso porque apesar de estarem presentes, a ordem social lhes assigna um lugar subordinado, complementar e tutelado.

Não obstante, o desenvolvimento industrial capitalista contribuiu para engendrar um nova personagem, as trabalhadoras, que, como grupo social visível, interpela o conjunto da sociedade que passará a estabeler-lhes disciplinas, normas, valores, enfim, discursos oficiais para dar conta desse fenômeno do trabalho feminino, inicialmente fabril, no século XIX.

A possibilidade de múltipla identificação, que a ampliação do trabalho assalariado para a mulher introduz, começa a inscrever-se no horizonte. Esse momento histórico é interpretado por Perrot como tendo um significado germinal para o imaginário social sobre as mulheres e para elas :

"Ora, essa representação totalizante (da mulher) desfaz-se progressivamente e as identidades femininas parecem multiplicar-se ; a mãe, a trabalhadora, a celibatária, a emancipada, etc. São qualidades próprias de uma ou outra mulher, vividas frequentemente de maneira contraditória, submetidas a tensões que anunciam a vida das mulheres no século XX".
É verdadeiramente fascinante seguir os percursos das historiadoras que vão mostrar que, para além das agruras da condição feminina, suas vidas se alteram e elas revelam-se também protagonistas da cena histórica.

Paradoxalmente, diante da diversidade das escolhas das mulheres, paralelamente se constrói e se fortalece, ou se consolida no século XIX, a separação entre o espaço público e o espaço privado. E o destino das mulheres atado ao privado, passa a ser normatizado por um discurso oficial amparado pela ciência, que lhes atribui lugares compatíveis com uma suposta essência feminina : ensinar, tratar, assistir, auxiliar; todas atribuições complementares que configurarão as profissões femininas aparentemente ancoradas por essas "qualidades naturais".

A dualidade produção/masculina e reprodução/feminina norteará as representações sociais e constituirá uma tensão sempre presente nas relações onde o trabalho feminino aparece.

O discurso essencialista sobre a natureza feminina contribuiu inclusive para usurpar os saberes e as práticas que as mulheres acumularam frequentemente de modo não formal. Outra dualidade se estabelece, com a identificação da cultura aos homens e da natureza às mulheres. Essas dualidades ou dicotomias cristalizadas em diversas representações tornaram-se historicamente componentes das relações de gênero e expressam nuclearmente o controle social masculino sobre as mulheres no âmbito das relações sociais mais amplas.

A categoria gênero como diz Joan Scott (1991), refere-se às representações socialmente construídas entre o masculino e o feminino nas diversas sociedades e que implicam em relações de poder assimétricas e hierárquicas, subordinado $o$ feminino ao masculino nas relações sociais em geral. Considera-se aqui, gênero, como um dos eixos fundamentais do ordenamento social, assim como, classe e raça/etnia, compondo um feixe de relações que estruturam e potencializam-se mutuamente nos processos histórico-sociais. Gênero, como categoria relacional, explicativa dos diferentes lugares sociais designados a homens e mulheres na sociedade, determinando distâncias e desigualdades sociais, permite olhar de modo novo o aparecimento de diferentes sujeitos sociais.

As mulheres populares no entanto, sempre trabalharam, mas por não serem submetidas ao 
assalariamento formal, essas atividades de trabalho nunca foram computadas como produtivas.

Perrot mostra que mesmo a filantropia, trabalho voluntário das mulheres, embrião do "trabalho social", contribuiu para que segmentos de mulheres modificassem "sua percepção do mundo, idéias que tinham de si mesmas, e até certo ponto, a sua inserção pública". (Perrot, op. cit. p. 504) As mulheres assim, estabeleceram laços na cidade e no Estado. Isso foi fundamental para as mulheres de classe média. Alerta entretanto, que, sintomaticamente, no final do século XIX, a gestão do social passa para mãos masculinas.

Ao longo de séculos, práticas de trabalho das mulheres estão embutidas no mundo do "não trabalho", ou seja, interpretadas como não trabalho. Esse é um dos lados do problema que reaparece no século XX, com o grande pêso da participação feminina para transformar as condições de vida nas comunidades. $\mathrm{O}$ trabalho voluntário das mulheres nos movimentos sociais retoma esse veio e tradição.

\section{O trabalho das mulheres como construtor de identidades}

O que importa remarcar até aqui é o fato de que diferentes práticas sociais das mulheres são para elas dotadas de sentido, de fortalecimento de laços de sociabilidade e de pertencimento e mais do que isso de um espelhamento de sua própria imagem, que as construções dominantes de gênero esmaecem.

Não foi por acaso que o feminismo emergiu no século XIX, ligado à mudanças estruturais, como o trabalho assalariado e, subjetivas, como o concomitante aparecimento das mulheres coletivamente no espaço público. Nesse momento histórico em que a vida cotidiana das mulheres se altera, surgem discursos explicativos, como o feminismo, que aliado às utopias socialistas e libertárias colocam no horizonte a emancipação das mulheres, objetivo a ser perseguido no caminhar constante da contestação das dsigualdades de gênero, possível também devido aos demais postulados da modernidade : liberdade individual e autonomia do sujeito.
Portanto, o trabalho, no plano simbólico, torna-se um veículo fundamental para a construção coletiva da identidade das mulheres.

Devemos tomar a identidade como um conceito eminentemente relacional, porque é socialmente construída por processos de identificação, de pertencimento e por processos de diferenciação, pela alteridade, no caso com trabalhador masculino. (cf. J. M. Pinto, 1991)

A identidade de trabalhadora, de reconhecer-se frente a outras iguais a si e diferente, frente aos companheiros de classe ou aos patrões, instala contradições e ambigüidades. No jogo de espelhos da identidade de trabalhadora, significados são construídos coletivamente, convergentes junto aos companheiros e em oposição aos patrões, mas por vezes divergentes dos companheiros. Tensões que instalarão significados coletivos sempre em aberto, em busca de alterar relações de gênero no campo do trabalho.

Pois, se o trabalho é uma das fontes de produção da identidade social (de resto o é também para os homens), se manifesta de modo duplamente forte para as mulheres, pois propicia a construção de um discurso de sujeito, de um "Nós", até então vedado às mulheres. Mesmo que a constituição da identidade seja concretamente múltipla e diferenciada, expõe e socializa de algum modo no espaço público, as trajetórias sociais das mulheres, e passa a interpelá-las como trabalhadoras.

Não é o trabalho em si, o foco principal de atenção nessa discussão, pois, via de regra, ele é inserido de modo subordinado no contexto das relações sociais, mas o mais importante é o feixe de relações sociais em que está inserido, sinalizando com a possibilidade de estabelecimento de projetos de vida diferenciados para as mulheres, vislumbrados, reais ou imaginariamente na cena histórica, ou melhor, na vida social.

Vemos cada vez mais desenvolverem-se diferentes modos de inserção das mulheres no mercado de trabalho e diferentes estratégias de sobrevivência, mas, do ponto de vista da dimensão simbólico cultural do trabalho, no caso das mulheres, o sentido das diferentes tentativas é sobretudo emancipatório, mesmo reconhecendo-se o lado pesado e opressivo que o mundo do trabalho reserva frequentemente às mulheres. Portanto, a possibilidade de lutar por um lugar e não aceitar simplesmente o lugar convencional (ou "não lugar") inscreve-se no real. 
As trabalhadoras, como sujeito coletivo, ao identificarem-se como tal, liberam energias emancipatórias que se depreendem da descoberta da realidade dura que o trabalho feminino configura : desigualdades, subordinações, superexploração, desvalorização, desqualificação. Como se, à descoberta de que é preciso lutar para sobreviver, junto aos demais trabalhadores, e de que são capazes de fazê-lo também, lhes trará fôlego dobrado para superar obstáculos adicionais advindos da divisão sexual do trabalho.

É evidente que não existe um sentido único para travar essa batalha do trabalho levada pelas mulheres. Algumas o fazem opondo-se às construções de gênero predominantes no trabalho, buscando participar de greves, sindicatos, atuações coletivas, etc. ; outras resistindo como podem no cotidiano de trabalho.

Outras ainda, buscando o sentido do trabalho nos espaços do não trabalho: em práticas de trabalho não assalariadas, como no trabalho pela comunidade, nos movimentos sociais, onde as mulheres tem sido presença constante, muitas vezes ignorada.

São espaços onde o trabalho é dotado de sentido voluntário, "não alienado", escolhido, trabalho e não labor, na categorização de $\mathrm{H}$. Arendt. Trabalhar, ou criar, seja pelo bem comum, pela justiça, pelos direitos, pela solidariedade, é atividade criativa e não labor, manifestação predominante do trabalho no capitalismo.

As mulheres não são passivas, nem submissas, vão construindo sua identidade ao perceberem que têm voz e vez nas práticas sociais. Descobrem e desconstroem sua subordinação, explicam-se, produzem identidades sociais, seja como trabalhadoras, militantes, participantes de obras coletivas.

Não é à toa que o trabalho comunitário ou os movimentos sociais com maciça participação feminina produzem lideranças, que no processo redefinem sua identidade de mulheres e acabam por relacionar-se com o espaço doméstico de modo novo, recriando suas subjetividades individuais e coletivas.

Assim, vemos configurar-se práticas de trabalho definidas pela ação e pelo discurso, nas conceituações de Arendt, que voltaremos ainda a mencionar.

O trabalho é cada vez mais rediscutido pela teia de relações sociais em que ele se estabelece, como é percebido e avaliado pelos agentes sociais. A produção da identidade no e pelo trabalho deve ser visto como um processo coletivo em constante redefinição.

O trabalho das mulheres hoje nos coloca novos desafios: a feminização da força de trabalho crescente; a volta ao trabalho fragmentado no espaço doméstico; enfim, a feminização do trabalho e da pobreza, acenam com novos desafios para fazer frente às novas exclusões, no momento em que o século $\mathrm{XX}$ ainda assimila assustado as reivindicações por igualdade das mulheres no campo do trabalho.

O imaginário social do século XIX criou a imagem da trabalhadora e o século XX consolidou, não sem uma luta incessante sócio-cultural e simbólica, momento em que as mulheres foram construindo um discurso emancipatório, localizando o direito ao trabalho como um dos pilares na busca de auto-determinação, fundante do sujeito coletivo e importante para a formação da subjetividade da mulher na modernidade.

As mulheres vieram progressivamente suplantando a "mística feminina" que as afastavam da esfera "produtiva" (Saffioti). Hoje o trabalho da mulher definitivamente põe em xeque a divisão dicotômica entre a produção e a reprodução, mostrando a imbricação constante entre as duas esferas.

O capitalismo tem se apropriado de construções ideológicas e simbólicas para beneficiar-se do trabalho doméstico não pago das mulheres, não computado pela economia política, e para desvalorizar o trabalho assalariado das mulheres.

Numa dessas construções, é comum notarmos o trabalho das mulheres ser considerado como complementar no âmbito da família, mesmo que cada vez mais mulheres das camadas populares tornem-se chefes de família; por esse expediente, justifica-se o trabalho menor remunerado.

Outro dado: o trabalho doméstico, o cuidado com as crianças estão fora da esfera econômica, isto é não são economicamente computados . A profissionalização de alguns desses trabalhos, por exemplo, as creches, redefiniram relações e problematizaram cada vez mais o trabalho social das mulheres, antes gratuito e invisível.

Outro exemplo importante, é o trabalho das mulheres no campo, realizado junto à unidades familiares, que enquanto produtoras rurais lutam 
para o reconhecimento de seu trabalho que é diversificado: da casa, à roça e, que só recentemente puderam definir-se como trabalhadoras rurais portadora de direitos.

Quando os diversos modos de inserção das mulheres no que se considera mundo do trabalho servem de caminho para que as mesmas deixem de se ver enquanto objeto (veículos de produção e reprodução) e passem a ver-se como sujeito, questiona-se todas as múltiplas práticas: o trabalho fora de casa; o trabalho informal; o trabalho nos assentamentos rurais, mesmo o trabalho doméstico, possibilitam que as mulheres possam desconstruir a submissão, a subordinação e a dependência e possam ver-se como pessoas, dotadas de autonomia e portadoras de direitos.

Passaporte para a cena pública, muitas vezes primeiro passo para ensaios de ações políticas, o trabalho das mulheres, seja o assalariado ou o trabalho para a comunidade, por exemplo, nos mutirões dos movimentos de moradia; de Conselheiras da Unidades de Saúde, no Movimento Popular de Saúde, seja nas práticas sociais cotidianas nos acampamentos dos Sem Terra, enfim, situam-nas na vida social. O trabalho interpela as mulheres para uma fala própria, para situarem-se na vida ativa.

Ao verem-se espelhadas em suas iguais, embora não de modo idêntico, a possibilidade de configuração de uma identidade de gênero torna-se concreta.

As trabalhadoras, por diversos modos $\mathrm{e}$ histórias pessoais e de lutas, têm chegado a fazer contato, no sentido da auto-consciência do problema, com essa dimensão presente nas relações sociais cotidianas.

\section{Trajetórias exemplares}

Reproduzo um depoimento exemplar da atualidade dessa problemática : A trajetória de Lucy, uma metalúrgica é expressão de um dos muitos caminhos que as mulheres trilharam ao se assumirem como trabalhadoras :

"Eu Lucy Paulino de Aguiar, 33 anos, operária de fábrica, acabo de ser admitida na executiva nacional da CUT. Pois andam dizendo que o Vicente Paulo da Silva, (. ..) cavou minha promoção. O companheiro Vicentinho não precisou cavar nada. Eu é que fui indicada pelos trabalhadores para assumir uma posição de comando na hierarquia sindical. E acho que fiz por merecer. Quero mais é lutar pelos direitos da mulher trabalhadora. Temos que avançar e muito. No ano passado, defendi na FIESP a licença de 3 meses e o auxílio maternidade para as mães adotantes. Perdi feio. Passou apenas a licença de 30 dias. Mas eu não desisto podem me aguardar. Não virei dirigente sindical nos salões da FIESP. Comecei por baixo. Lembro da primeira vez em que participei de uma assembléia de metalúrgicos. Foi em 1984 no ABC. Tomei o maior susto. Só tinha homem. Um bando de machos. Quando eu cheguei, um gritou : "olha a gosotosna". Todos me olharam. Fui para o fundo do salão e quase morri de vergonha. Passei, então, a conviver com os preconceitos desse mundo. Mulher sindicalista, dizem, é feia, malamada, sem vergonha ou sapatão. Sobrevivo.

Primeiro aprendi a ser operária. Depois, sindicalista. (, ..) Me criei na linha de produção efui me apaixonando pela metalurgia. (. ..) O estalo aconteceu em 1984, durante uma greve na Brosol. Queríamos apenas formar uma comissào de fábrica e os patrões responderam com 120 demissões. Foi barra pesada, eu já vinha sentindo na pele a discriminação da mulher ; quantas de nós éramos contratadas como auxiliares de montagem mas, na prática, trabalhávamos como montadoras sem salário merecido? As chefias masculinas controlavam o banheiro feminino. Só permitiam duas idas pela manhã e duas à tarde. E rápido. Imagine a situação da operária que menstrua ao longo do dia e que não ganha a chave do lavatório . Me senti humilhada e resolvi brigar. (. ..) Quero deixar claro: o sindicato não me formou. Eu é que me formei no sindicato. Já organizei greve, já enfrentei polícia, já parei fábrica. Nada disso me assusta. "(Veja Especial Mulher, ag/set. 1994)

É interessante ressaltar no depoimento acima, inúmeras questões, tais como o fato do sindicato ser um espaço masculino, onde os companheiros ainda vêem a liderança feminina com desconfiança, quando não com desqualificação. Outra observação relevante, é o fato de demonstrar a possibilidade de encontrar sentido para o trabalho, seja de criatividade, seja de auto-reconhecimento da capacidade de desenvolver-se ; "Fui me apaixonando pela metalurgia". Faz ainda uma descrição do modo de operar a máquina, entre outras questões que não cito aqui para não alongar 
demais o texto, que mostra que a mulher não é simplesmente um "agente de produção". Pensa, sente, reage, fazendo-o constantemente, não obstante, relate algumas das agruras da divisão sexual do trabalho.

Diante da opressão exclusiva do privado que vivem inúmeras mulheres que não lograram outro tipo de inserção na vida social, o trabalho como direito a uma vida coletiva, inscreve-se como possibilidade. Sentir-se pessoa em busca de cidadania é uma outra manifestação da atividade de trabalho para as mulheres por mais difícil que sejam as condições de vida e de trabalho. Podemos vislumbrar uma ampla gama de destinos traçados e experiências práticas diversas, que exigem alto grau de reflexividade, no sentido de ter que tomar decisões. Buscar o destino e não simplesmente aceitar o inevitável é um dos sentidos possíveis. Nessa perspectiva é possível também entender as mulheres migrantes.

\section{A migrante em busca de trabalho: Uma outra história exemplar}

Um depoimento revelador das diferentes maneiras de luta das mulheres onde o trabalho tem um papel construtor da identidade é o da presidente do sindicato das empregadas domésticas do Rio de Janeiro, exemplificando o sentido de autonomia e identidade:

"Nasci na cidade de Mundo Novo, no alto sertão da Bahia (...) filha de mãe analfabeta. Diziase que mulher não precisava estudar. Não tinha certidão de nascimento, só tinha um papel caseiro dizendo que eu era Maria de Lourdes Jesus. Um dia fui com a vizinha me matricular numa escola. "a fulana de tal botou os filhos na escola muito cedo e eles ficaram malucos', reclamou minha mãe. (. ..) $\mathrm{Na}$ minha rua eu fui aprimeira a ir para a escola com 6 anos. (. ..) Uma beleza. Aos 9 anos comecei a tentar trabalhar. Ajudava um vizinho que fazia doce de banana e mamão para vender na feira. $\mathrm{Na}$ hora de lavar aqueles tachos enormes de cobre, os filhos e netos dele achavam feio fazer trabalho de mulher - arear panela, com areia mesmo, porque bombril vim conhecer só aqui no Rio. Eu ganhava aquele dinheirinho para a merenda.
Também quebrei pedra- é, pedra mesmo. Lá no sertão não tinha máquina de fazer concreto, era tudo na mão. (. ..) Hoje em dia tenho muito orgulho de tudo isso. Olho para trás e mal acredito. Terminei o ginásio com dificuldade, não tive condição de fazer o mestrado que eu tanto queria. Mas adquiri o diploma para poder fazer alfabetização. Fui ser professora primária rural (...) Saí de lá com 27 anos, quando a esposa de um fazendeiro alemão me falou: 'Lourdes você conhece alguém que queira ir trabalhar lá no Rio com minha família ? Eles estão pagando 100 cruzeiros. Era um montão de dinheiro - agente ganhava 5 lá no sertão. Então pensei: Vou eu' . Ganhando 100 cruzeiros recomeço meus estudos e aí vou mesmo pra frente. Eu já tinha trabalhado num hospital lavando chão, atendendo na farmácia cheguei a aplicar injeção. Então pensei que já sabia muito, que no Rio eu ia poder escolher, e fazer e acontecer e fazer uma faculdade. Eu ia poder fazer Direito - sempre achei Direito bonito e importante. Ou ser aquela professora que ia poder ensinar no Ginásio". Ai, meu Deus! Cheguei no Rio de Janeiro e não foi nada disso.

Como a família havia pago a passagem, me pediram para eu ficar pelo menos uns 6 meses. Bom, aceitei para ficar livre do compromisso.

Comecei a pensar em estudar à noite, mas não consegui de jeito nenhum. Os horários da casa não permitiam. (...) O tempo foi passando e eu arrumei um supletivo por correspondência. Levei 5 anos. Mas me formei pelo Mobral. Uma beleza me ajudou muito. Também consegui fazer curso de datilografia, manicure (...)

Um dia, em 1973, ouvi no radio que a empregada doméstica tinha direitos. 'Tenha sua carteira assinada"diziam. (...) Eu tenho essa coisa de lutar sem ficar injuriada. $\mathrm{Na}$ esquina do meu trabalho, em Ipanema, tinha uma igreja onde um grupo de legionárias sempre falava das empregadas domésticas querendo ajudar. Faziam missa no dia de Santa Zita Nossa Padroeira. Todo ano eu ia, mas achava esquisito quando colocava aquela coisa de humildade de Maria. Eu não achava certo ter que sempre abaixar a cabeça. Mas não é isso gente! Um dia numa dessas missas, fiquei olhando 2 moças que distribuiam papéis na porta. Peguei um na saída, dobrei com cuidado e só fui ler em casa : Associação das Domésticas do Rio de Janeiro. Foi em $85 / 86$, por aí. Antes eu já tinha visto uma reportagem muito bonita numa revista que dizia que 
a doméstica trabalhava mais do que o escravo na época da escravidão, mais de 14 horas. Foi o começo do meu caminho de me juntar a outras. Hoje sou presidente do sindicato de Domésticas do rio, onde somos 90. 000. Estou com 50 anos, continuo trabalhando na mesma casa e ganho 1,7 salário mínimo. Mas a vida é minha e sou eu quem a conduzo. Faço do meu trabalho uma profissão digna pois se eu mesma não valorizo o que faço como é que vou me valorizar como pessoa?

Muitas companheiras têm vergonha de ser doméstica, nem querem o registro em carteira. É terrível, porque vem a doença, vem a idade, ficam desamparadas (...) Das minhas amigas (da Bahia), nõ sei explicar, sinto pena, são até mais novas do que eu, mas estão acabadas, desvalorizadas, parecendo ter tantos anos a mais! Fico na janela olhando para a mesma rua de terra e vejo aquelas mulheres subindo com a roupa na cabeça - não mudou nada! Elas têm um monte de crianças. E os maridos, que se você olhar direito não estão muito melhor, sempre se sentindo superiores (. ..) Namorados sempre tive. Brinco que não sou solteirona, sou solteiríssima. Fui noiva durante 9 anos, mas decide que não iria segurar barra de homem de vida desregrada. Enquanto eu viver como mulher, sou eu quem toma conta de mim . Uma beleza. " (Veja Especial Mulher, 1994)

Analisar as trajetórias de mulheres e localizar no cotidiano, no conjunto da vida, como o trabalho se situa é bastante enriquecedor. No depoimento acima, também a consciência de gênero aflora. $O$ que é comum aos trabalhadores em geral aparece, mas o que é diferente salta aos olhos na construção social da identidade feminina (Neves, M. 1995).

Lá, a autora mostra que as mulheres também colocaram-se em busca de cidadania, pois passaram a representar-se no espaço social em ações operárias e não operárias. Neves capta nas experiências das mulheres, as "pequenas ações invisíveis no espaço da produção"que podem desaguar por vezes na experiência coletiva da greve, e que podem, ao fazê-lo, trazer para as próprias mulheres novas significações. Muitas descobrem um modo comum de ser e estar no conjunto das relações sociais que se estabelecem. Descobrem as relações de gênero no espaço do trabalho; Vêem-se como subordinadas, ou melhor, representadas socialmente de modo subordinado, desigual, inferiorizado e hierarquizado.
É evidente que custa caro, nos diferentes espaços de trabalho, a tentativa de igualar-se ao trabalhador: a divisão sexual do trabalho, como um dos "locus das relações de gênero"(Lobo, 1991), mostra bem a dimensão do esforço, nem sempre possível.

Por outro lado, para a maioria das mulheres o trabalho remunerado significa frequentemente uma tensão entre o esforço que ele acarreta para a conciliação com a responsabilidade quase exclusiva da reprodução social. Nem sempre trabalhar fora implica rever a divisão dos papéis sexuais, a divisão das tarefas domésticas e de educação dos filhos. Não obstante, práticas de trabalho formalizadas ou não, permitem às mulheres autovalorizar-se. Possibilita questionar laços concretos de dependência (pai, marido, patrão, etc.). Esse aspecto é interessante, porque às mulheres historicamente sempre lhes foi assignada uma educação nos limites do útil: "saber-fazer e sabermostrar"(Fraisse e Perrot), saberes aliados às tarefas de mãe, dona de casa e esposa. No passado os cursos eram diferenciados para elas, incluiam prendas domésticas e bordados, etc.

As representações rígidas dos papéis sexuais, mais da ordem do simbólico, como momento das relações de gênero, é interiorizado pelas mulheres que necessitam perfazer um longo percurso se quiserem romper com a imagem de trabalhadora "de segunda classe". Suas qualidades, capacidades, talentos ou qualificações são via de regra desconsideradas, colocadas sob suspeita, seja nas fábricas, bancos, escritórios, propriedades rurais, etc.

Em 1994, a UNICEF divulgou um dado importante: as mulheres efetuam $2 / 3$ das horas trabalhadas no mundo e só possuem $1 / 10$ dos bens mundiais. Essa estatística demonstra bem a dura inserção das mulheres, de forma subordinada no mercado de trabalho e o impacto concreto nas suas condiçoes de vida. A luta contra a degradação, desvalorização e invisibilidade do trabalho das mulheres continua na ordem do dia .

É como se hoje, as mulheres estivessem vivendo em temporalidades variadas do ponto de vista da valorização do próprio trabalho. Ao inserirem-se em práticas sociais as mais diversas, além do papel tradicional de donas de casa, podem encontrar formas ou modos de pensar na possibilidade de perfazer o percurso simbólico de 
auto-constituição enquanto seres integrais, com múltiplas facetas.

Uma outra dimensão do trabalho pode ser apreendida quando a divisão tempo-espaço do trabalho assalariado não conta, como no caso da trabalhadora rural. Assumir essas identidade de trabalhadora diferenciada, possível recentemente, amparada pelas recem-conquistadas reivindicações de trabalhadora rural, foi outro percurso difícil mas em muitos casos criador de uma identidade:

"Aprendi que mulher da terra não é doméstica, não. É trabalhadora rural. E trabalhadora rural tem direitos. Como lider do Movimento de Mulheres de Petrolândia, PE, já corri mundo. Fui me encontrar com as canavieiras de Nazaré da Mata. Lá não existe barragem. Mas existe um sistema de trabalho desumano, o dia inteiro cortando cana para ganhar um nadinha de dinheiro e muitas vezes esse dinheiro é pago diretamente aos homens da casa. Mulher não pega em dinheiro, mas lava, passa, cozinha, embucha, cria filho, e também pega na enxada. Eu fico brava com esse jeito de viver. afinal, a mulher do campo vira um traste qualquer. Não aceito, e digo o que sinto. Sou faladrira, não sou?'( Nanô. Veja Especial Mulher, 1994)

É interessante observar além da compreensão da especificidade da mulher que trabalha na terra, como sua prática nos movimentos sociais contribuiu para fazê-la representar-se com orgulho como trabalhadora rural.

Se considerarmos a categoria gênero como relacional, pressupondo a construção históricocultural de subjetividades em constante interação social, tratando das representações do masculino e feminino socialmente elaboradas, importa perscrutar as brechas e os momentos que as mulheres encontram para construirem uma identidade de trabalhadora e de sujeito sexuado que justamente colocarão em questão as relações de gênero enquanto assimetrias de poder na interação masculino-feminino.

A historiadora Joan Scott, em brilhante texto: "As trabalhadoras", desconstrói o discurso sobre o trabalho da mulher no século XIX, apontando-o como "o discurso que no século XIX conceitualizou o gênero como uma divisão "natural"que deve ser lido no contexto geral da retórica do capitalismo industrial sobre a divisão do trabalho". (Scott, 1994) .

Para Scott, o discurso centrado no gênero (nas diferenças atribuídas aos sexos) é tomado como fato social objetivo. Além disso, segundo esta autora, é o discurso sobre o valor do trabalho feminino que se consolida entre os patrões, que sedimenta a mão de obra feminina como barata; solidifica a preferência pelas jovens e solteiras, pois a alegada incompatibilidade entre domesticidade e trabalho é mais um manto justificador da discriminação das mulheres. Portanto, a divisão sexual do trabalho vem a ser para Scott "produto da história, efeito do discurso". A ordem social, enfim, consolida essa imagem da mulher trabalhadora com as bênçãos da Economia Política.

A divisão sexual do trabalho como constructo histórico, como bem discutiu Scott, apropriado pela lógica capitalista de normatização do trabalho está sendo vista nesse contexto como um espaço estruturante dos limites reais em que operam as subjetividades concretas das trabalhadoras.

Os depoimentos trazidos aqui à discussão, são uteis para mostrar manifestações concretas de como se dá a intersecção da experiência vivida no trabalho na resignificação e releitura de relações sociais mais amplas. Mostram modos e estilos de como as mulheres integram desejos e necessidades e nesse âmbito integram e interpretam o trabalho no re-tecer de suas histórias de vida.

O significado simbólico maior do trabalho para as mulheres, seja tanto estabelecendo transgressões e rebeldias nos marcos estreitos das possibilidades de trabalho da maioria delas, seja aceitando ou negando o trabalho como sofrimento, é que a singularização das subjetividades, as vivências femininas do trabalho são fundamentais num processo do ver-se como pessoa. Numa abordagem Yunguiana, diríamos no processo de individuação.

O plano do simbólico e da subjetividade é comumente esquecido nas relações de homens e mulheres com o trabalho no âmbito da sociologia do trabalho. A contribuição da psicologia pode iluminar esse aspecto. Nesse caso, é útil a definição do psicólogo Yunguiano Côrrea Sales, pois para ele “(. ..) a individuação, se trata, portanto, em primeiro lugar, de um processo subjetivo de integração e, em segundo lugar, de um processo indispensável de integração objetiva". (citado por Castro, Mary, 1992).

Pensar em significados do trabalho para as mulheres, portanto, passa inevitavelmente pela reterritorialização da subjetividade como processo em aberto no campo do questionamento das 
relações de gênero que plasmam a ordem social contemporânea.

Essas considerações permitem um diálogo com a obra de $\mathrm{H}$. Arendt, que nos aponta três aspectos da condição humana : a do labor, atividade que corresponde ao processo biológico de reposição da vida. A condição humana do labor é a própria vida; a do trabalho, correspondente ao mundo artificial das coisas. A condição humana do trabalho é a mundanidade; a da ação, a única atividade que se desenvolve diretamente entre os homens sem a mediação das coisas e da matéria. A condição humana da ação é a pluralidade. Esta pluralidade que diz respeito às diferenças entre os homens é especificamente, a condição de toda a vida política. (Arendt, H. , 1993:15)

Não se pode negar estes aspectos da condição humana, pois a negação de qualquer deles significa não ter lugar reconhecido no mundo, nas relações sociais. Para as mulheres, o significado subjetivo de ter um lugar, de visibilizar-se pelo trabalho é fundamental para a sua identidade.

O trabalho é uma porta para o domínio público, espaço esse que segundo Arendt, quando não está obscurecido (no sentido de livre), tem como função iluminar a conduta humana permitindo a cada um, mostrar através de palavras e ações, do que é capaz. Para Arendt, é no espaço da ação que se encontra o único meio de reger o próprio destino. $\mathrm{Na}$ ação se expressa a singularização individual : "a ação é a fonte do significado da vida humana. É a capacidade de começar algo novo que permite ao indivíduo revelar sua identidade". Esse é um dos modos de se refletir sobre a vida ativa. É muito importante para as mulheres deparar-se com as características do domínio público, a palavra e a ação, pois elas estão em oposição à opacidade e ao silêncio do espaço privado, como é o espaço doméstico, entre quatro paredes, que o imaginário social criou como destinação natural para as mulheres. Isto, inúmeras práticas de trabalho propiciam.

Buscar pistas para recuperar os significados do trabalho para as mulheres é reinscrever o trabalho como dotado de sentido, como obra, distante da focalização única do processo de trabalho, do conteúdo das tarefas. Seguindo a tradição de Arendt, é importante compreender e atribuir um sentido, como um processo complexo, "como uma incessante atividade sempre variada em mudança, por meio do qual nos ajustamos ao real".
A compreensão de si mesma e do mundo é criadora de sentido, "que se enraiza no próprio processo da vida na medida em que tentamos, através da compreensão, conciliar-nos com nossas ações e paixões. (Lafer. apêndice. Arendt, 1993)

O isolamento do trabalho doméstico, como todo isolamento que bloqueia laços, é base de opressões, dominações e mesmo tiranias. Enquanto que o trabalho "lá fora", assalariado ou voluntário, social (visto como não trabalho), na comunidade, permite, não só à mulheres, mas a ela fortemente, desenvolver relacionamentos sociais que podem dar origem à ação, permitindo como retorno desse processo inclusive, a ressignificação do trabalho doméstico ou no campo, ou seja, valorização do que não tem valor aparente.

Isto possibilita compreender o grande investimento simbólico embutido no trabalho pelas mulheres, atividade valorizada socialmente, porta de entrada para o mundo público, para o mundo da ação, em que pese a desvalorização do trabalho feminino, é o espaço onde é possível estar em busca de redesenhar significados em meio às demais práticas sociais.

Definir-se como trabalhadora, construir a identidade através do discurso e da ação, revelam um sujeito social novo, para si e para os outros, que não pode mais ser definido como complementar, apêndice, mas que pode ousar aparecer vez por outra como autoras, atrizes de uma outra história que ora apenas se ensaia, ora se concretiza.

Perrot ao resgatar os diversos modos de expressão da mulher popular rebelde para confrontar os discursos modernos solidificados no século XIX, que tão bem justificou a separação do espaço doméstico do espaço público, vai mostrá-la em ações criativas e irreverentes:

"As mulheres não são passivas, nem submissas. A miséria, opressão não bastam para contar a sua história. Elas estão presentes aqui e além. Elas são diferentes. Elas se afirmam por outras palavras, outros gestos. $\mathrm{Na}$ cidade, na própria fábrica, elas têm outras práticas cotidianas, formas concretas de resistência - à hierarquia, à disciplina - que derrotam a racionalidade do poder, enxertadas sobre seu uso próprio do tempo e do espaço. Elas traçam um caminho que é preciso reencontrar. Uma história outra, uma outra história". (Perrot, Os excluídos da História, 1986).

Diversas práticas de trabalho permitem à mulher questionar a sua condição de ser mulher. 
Como enunciou Arendt, "sem discurso, a ação deixaria de ser ação, pois não haveria ator; e o ator, agente do ato, só é possível se for, ao mesmo tempo o autor de palavras. A Ação que ele inicia é humanamente revelada através de palavras;e, embora $o$ ato possa ser percebido em sua manifestação física bruta, sem acompanhamento verbal, só se torna relevante através da palavra falada, da qual o autor se identifica, anuncia o que fez, faz e pretende fazer".

A capacidade de nomeação das práticas de trabalho exercidas pelas mulheres, e de se explicarem a si mesmas que elas adquirem pelo trabalho, tem tido um potencial emancipador.

A possibilidade de visualizar e nomear o trabalho, seja como necessidade, escravidão, trabalho oprimido e cerceado; seja como criativo e libertador, representa vida ativa, dotada de vontade, diferentemente da vida indistinta, sem definição, quando remetida somente ao espaço invisível e isolado do privado.

Relendo Arendt em sua valorização da ação, realça-se que "essa qualidade reveladora do discurso e da ação vem à tona quando as pessoas estão com outras, isto é, no simples gozo da convivência humana". Práticas de trabalho permitem estar em relação, na condição humana da mundanidade, uma mediação necessária para a ação. O trabalho pode significar para as mulheres estar disposta a correr o "risco da revelação", porque estar juntas, mesmo em meio à dificuldades, nos remete a desafios identitários.

\section{Referências Bibliográficas:}

Arendt, Hannah. A Condição Humana. Rio de Janeiro. Forense Universitária. 6a. ed. 1993.

Blass, Leila. "Gênero e Trabalho: Trajetórias de uma problemática". In Adorno, S. (org.) A sociologia entre a modernidade e a Contemporaneidade. Porto Alegre:Ed. UFRJ/Soc. Bras. de Sociologia. 1995.

Castro, Mary G. "O conceito de gênero e análises sobre mulher e trabalho: Notas sobre impasses teóricos". Cadernos C. R. H. Salvador, 1992.

Freyssenet, Michel. "Quelques pistes nouvelles de conceptualisation du travail". Sociologie du Travail. Paris: n. Hs/94.

--antion du travail". Futur Antérieur. n. 2, Paris, 1994.

Fraisse, G. e Perrot, M. Introdução. História das Mulheres. O século XIX. v. 4. Porto: Afrontamento, 1994.

Neves, Magda A. Trabalho e Cidadania. As trabalhadoras de Contagem. Rio de Janeiro: Vozes. 1995.

Perrot, M. "A mulher popular rebelde". Os excluidos da história. Rio de Janeiro: Paz e Terra, 1986.

Pinto, José M. "Considerações sobre a produção social da identidade". Revista Crítica de Ciências Sociais, n. 32. Junho de 1992. Porto.

Santos Silva, A. "Identidades Sociais. Continuidade e Mudança “. III Congresso Luso-Afro-Brasileiro de C. Sociais. Lisboa, 1994.

Scott, Joan. "A mulher trabalhadora". in: História das Mulheres, v. 4. Porto: Afrontamento, 1994.

Scott, Joan. "Gênero: uma categoria util de análise Histórica". in Educação e Realidade. Porto Alegre, v. 16, n. 2, 1990.

Souza Lobo, E. A classe operária tem dois sexos. São Paulo: Brasiliense, 1991.

Veja Especial Mulher. Agosto/setembro de 1994. 